Department of

Economics and Finance

Guglielmo Maria Caporale and Luis A. Gil-Alana

Multi-factor Gegenbauer Processes and European I nflation Rates

February 2009 


\title{
MULTI-FACTOR GEGENBAUER PROCESSES AND EUROPEAN INFLATION RATES
}

\author{
Guglielmo Maria Caporale \\ Brunel University, London
}

\author{
and \\ Luis A. Gil-Alana \\ University of Navarra
}

February 2009

\begin{abstract}
In this paper we specify a multi-factor long-memory process that enables us to estimate the fractional differencing parameters at each frequency separately, and adopt this framework to model quarterly prices in three European countries (France, Italy and the UK). The empirical results suggest that inflation in France and Italy is nonstationary. However, while for the former country this applies both to the zero and the seasonal frequencies, in the case of Italy the nonstationarity comes exclusively from the long-run or zero frequency. In the UK, inflation seems to be stationary with a component of long memory at both the zero and the semi-annual frequencies, especially at the former.
\end{abstract}

JEL Classification: C22, O40

Keywords: Fractional Integration, Long Memory, Inflation

Corresponding author: Professor Guglielmo Maria Caporale, Centre for Empirical Finance, Brunel University, West London, UB8 3PH, UK. Tel.: +44 (0)1895 266713. Fax: +44 (0)1895 269770. Email: Guglielmo-Maria.Caporale@,brunel.ac.uk

The second-named author gratefully acknowledges financial support from the Ministerio de Ciencia y Tecnologia (ECO2008-03035 ECON Y FINANZAS, Spain). 


\section{Introduction}

Modelling inflation is still a controversial issue, and a consensus is yet to be reached on whether it is a stationary $\mathrm{I}(0)$ or a nonstationary $\mathrm{I}(1)$ variable. More recently, it has been suggested that it might be an I(d) process, with d lying between 0 and 1 . Such processes exhibit long memory, with a pole or singularity in the spectrum at the long-run or zero frequency. This idea was introduced in the mid-1960s by Granger (1966) and Adelman (1965), who pointed out that for most aggregate economic time series the spectral density has a typical shape with a spike as the frequency approaches zero, and differencing the data frequently leads to overdifferencing at the zero frequency. However, it might be that the series is characterised by more than one pole or singularity in the spectrum, but, given the strong influence of the component at the zero frequency, these poles may not be apparent in the periodogram or in any other estimate of the spectral density function. This is particularly relevant if seasonal components are present in the data, as, for instance, in the case of quarterly or monthly data. There exist procedures for estimating the fractional differencing parameter in this context using seasonal long-memory models; however, many of them have the limitation of imposing the same degree of integration at all frequencies in the spectrum. For instance, this is the case for the Dickey-Hasza-Fuller (DHF, 1984) tests for seasonal unit roots in a non-fractional context. ${ }^{1}$

By contrast, in the present study we specify a multi-factor long-memory process that enables us to estimate the fractional differencing parameters at each frequency separately, and adopt this framework to model quarterly prices in three European countries (France, Italy and the UK). The outline of the paper is as follows: in Section 2 we briefly review the literature on modelling inflation, focusing particularly on long-memory models.

\footnotetext{
${ }^{1}$ Hylleberg, Engle, Granger and Yoo (1990) present a procedure that allows one to consider unit roots at zero and each of the seasonal frequencies separately, although it focus exclusively on the $\mathrm{I}(0) / \mathrm{I}(1)$ cases.
} 
In Section 3 we describe the statistical framework employed here. Section 4 presents the empirical results. Section 5 analyses the forecasting performance of the model, whilst Section 6 summarises the main findings and offers some concluding remarks.

\section{Literature review}

The empirical literature on inflation is vast. In the last couple of decades attention has often focused on European countries, as inflation convergence is one of the requirements for EMU membership specified in the Maastricht treaty. Several studies have carried out standard unit root tests (see, e.g., Barsky, 1987, and Rose, 1988), with mixed results depending on the span of data. Long-memory models have then become increasingly popular (see, e.g., Chung and Baillie, 1993, and Franses and Ooms, 1997). Much of the evidence supports the view that inflation is fractionally integrated with a differencing parameter that is significantly different from zero or unity. For instance, using US monthly data, Backus and Zin (1993) found a fractional degree of integration. They argued that aggregation across agents with heterogeneous beliefs results in long memory in the inflation process. Hassler (1993) and Delgado and Robinson (1994) provided strong evidence of long memory in the Swiss and Spanish inflation rates respectively. Baillie, Chung and Tieslau (1996) examined monthly post-World War II CPI inflation in ten countries, and found evidence of long memory with mean-reverting behaviour in all countries except Japan. Similar results were reported by Hassler and Wolters (1995) and Baum, Barkoulas and Caglayan (1999). ${ }^{2}$

Other studies have also attempted to take into account possible persistence and heteroscedasticity in inflation rates (see, e.g., Chambers, 1998, Bollerslev and Wright,

\footnotetext{
${ }^{2}$ Other papers dealing with long memory in inflation rates in the context of structural breaks are Bos, Franses and Ooms (1999, 2001), Gadea, Sabate and Serrano (2004), Franses, Hyung and Penn (2006) and Gil-Alana (2008), and forecasting issues are examined in Franses and Ooms (1997) and Barkoulas and Baum (2006).
} 
2000, Ferrara and Guegan, 2001a). In particular, a general model, which extends the FIGARCH, FIEGARCH and FARMA-GARCH specifications of Baillie et al. (1996), Bollerslev and Mikkelsen (1996) and Ling and Li (1997), has been proposed by Guegan (2000). His framework combines long-memory behaviour with quasi-periodic behaviour in the conditional variance of the series.

\section{The statistical framework}

In this paper we consider various time series long-memory models. The first is the standard I(d) model given by

$$
\begin{aligned}
& (1-L)^{d} x_{t}=u_{t}, \quad t=1,2, \ldots, \\
& x_{t}=0, \quad t \leq 0 \text {, }
\end{aligned}
$$

where $x_{t}$ is an observable time series, or alternatively the errors in a regression model of the form:

$$
y_{t}=\beta^{\prime} z_{t}+x_{t}, \quad t=1,2, \ldots
$$

where $\mathrm{z}_{\mathrm{t}}$ are deterministic regressors such as an intercept $\left(\mathrm{z}_{\mathrm{t}}=1\right)$ or an intercept with a linear time trend $\left(z_{t}=(1, t)^{T}\right)$; $L$ is the lag-operator $\left(L y_{t}=y_{t-1}\right)$, $u_{t}$ is assumed to be $I(0){ }^{3}$ and, given the quarterly frequency of the data analysed here, to follow a seasonal autoregressive (AR) model of the form:

$$
\phi\left(L^{s}\right) u_{t}=\varepsilon_{t}, \quad t=1,2, \ldots
$$

where $s$ indicates the number of time periods per year, and $\epsilon_{t}$ is a white noise process. This specification implies that the long-run dynamic behaviour of the series is captured by the fractional differencing parameter $\mathrm{d}$ only, while the seasonal structure is a purely short-run phenomenon described by the AR coefficients.

A second model considered in this study is the seasonal I(d) process described by

\footnotetext{
${ }^{3}$ An I $(0)$ process is defined as a covariance stationary process eith spectral density function that is positive and finite at any frequency. It thus includes the stationary ARMA models.
} 


$$
\left(1-L^{s}\right)^{d} x_{t}=u_{t}, \quad t=1,2, \ldots
$$

where d once more can take a fractional value. Porter-Hudak (1990) applied a seasonally fractionally integrated model of this type to quarterly US monetary aggregates, and concluded that a fractional ARMA model was more appropriate than the usual ARIMA specification for these series. Other recent empirical papers on seasonal fractional integration using a model such as (5) for macroeconomic series are those of Gil-Alana and Robinson (2001) and Gil-Alana (2002). A limitation of this approach is that it imposes the same degree of integration at the zero and seasonal frequencies. For example, in the quarterly case, i.e., $\mathrm{s}=4$, the polynomial $\left(1-\mathrm{L}^{4}\right)^{\mathrm{d}}$ can de decomposed into (1$L)^{d}(1+L)^{d}\left(1+L^{2}\right)^{d}$ imposing the same degree of integration $d$ at all frequencies: the zero, semi-annual $(\pi)$, and annual $(\pi / 2$ and $3 \pi / 2)$ frequencies respectively.

The model in (5) can be generalised using multi-factor Gegenbauer processes. Specifically, we can consider processes of the form:

$$
\prod_{s=1}^{k}\left(1-2 \cos w_{r}^{(s)} L+L^{2}\right)^{d} x_{t}=u_{t}, \quad t=1,2, \ldots
$$

where $\mathrm{k}$ is a finite integer indicating the maximum number of cyclical (seasonal) structures. First we focus on the case of a single structure, i.e., $\mathrm{k}=1$,

$$
\left(1-2 \cos w_{r} L+L^{2}\right)^{d} x_{t}=u_{t}, \quad t=1,2, \ldots
$$

where $\mathrm{w}_{\mathrm{r}}$ and $\mathrm{d}$ are real values, and $\mathrm{u}_{\mathrm{t}}$ is $\mathrm{I}(0)$. For practical purposes we define $\mathrm{w}_{\mathrm{r}}=2 \pi \mathrm{r} / \mathrm{T}$, with $r=T / j$, and thus $j$ will indicate the number of time periods per cycle, while $r$ refers to the frequency with a pole or singularity in the spectrum of $x_{t}$. Note that if $r=0$ (or $\left.j=1\right)$, the fractional polynomial in $(7)$ becomes $(1-L)^{2 d}$, which is the polynomial associated to the common case of fractional integration at the long-run or zero frequency. This type of process was introduced by Andel (1986) and subsequently analysed by Gray, Zhang and Woodward (1989, 1994), Chung (1996a,b) and Dalla and Hidalgo (2005) among others. 
Gray et al. (1989) showed that, defining $\mu=\cos w_{r}$, the polynomial in (7) can be expressed for all $d \neq 0$ as

$$
\left(1-2 \mu L+L^{2}\right)^{-d}=\sum_{j=0}^{\infty} C_{j, d}(\mu) L^{j}
$$

where

$$
C_{j, d}(\mu)=\sum_{k=0}^{j} \frac{(-1)^{k}(d)_{j-k}(2 \mu)^{j-2 k}}{k !(j-2 k) !} ; \quad(d)_{j}=\frac{\Gamma(d+j)}{\Gamma(d)}
$$

and $\Gamma(x)$ is the Gamma function. Alternatively, we can use the recursive formula,

$$
\begin{aligned}
& C_{0, d}(\mu)=1, C_{1, d}(\mu)=2 \mu d, \text { and } \\
& \quad C_{j, d}(\mu)=2 \mu\left(\frac{d-1}{j}+1\right) C_{j-1, d}(\mu)-\left(2 \frac{d-1}{j}+1\right) C_{j-2, d}(\mu), \quad j=2,3, \ldots .,
\end{aligned}
$$

(see, for instance, Magnus et al., 1966, or Rainville, 1960, for further details on Gegenbauer polynomials). These authors also showed that $x_{t}$ in (7) is stationary if $d<0.5$ for $\left|\mu=\cos w_{r}\right|<1$ and if $d<0.25$ for $|\mu|=1$.

If there is more than one cyclical structure, then the appropriate specification is the multi-factor Gegenbauer process described in (6), with $w_{r}^{(s)}=2 \pi r^{(s)} / T ; \mathrm{r}^{(\mathrm{s})}=\mathrm{T} / \mathrm{j}^{(\mathrm{s})}$, where $\mathrm{j}^{(\mathrm{s})}$ indicates the number of time periods per cycle corresponding to the $\mathrm{s}^{\text {th }}$ cyclical structure. Empirical studies based on multiple cyclical structures (also named $k$-factor Gegenbauer processes) include Ferrara and Guegan (2001b), Sadek and Khotanzad (2004) and Gil-Alana (2007). In the case of quarterly time series data, we can generalise (5) by considering a model like (6) with $\mathrm{k}=3$, and

$\left(1-2 \cos w_{r}^{(1)} L+L^{2}\right)^{d_{1}}\left(1-2 \cos w_{r}^{(2)} L+L^{2}\right)^{d_{2}}\left(1-2 \cos w_{r}^{(3)} L+L^{2}\right)^{d_{3}} x_{t}=u_{t}$,

with $w_{r}^{(1)}=0$ or $2 \pi\left(\mathrm{r}^{(1)}=0, \mathrm{~T}\right), w_{r}^{(2)}=\pi\left(\mathrm{r}^{(2)}=\mathrm{T} / 2\right), w_{r}^{(3)}=\pi / 2\left(\mathrm{r}^{(3)}=\mathrm{T} / 4\right)$, implying that (8) can be written as 


$$
(1-L)^{2 d_{1}}(1+L)^{2 d_{2}}\left(1+L^{2}\right)^{d_{3}} x_{t}=u_{t},
$$

which is a seasonal long-memory model with different orders of integration at each of the frequencies.

\section{Empirical evidence of long memory in European prices}

The series analysed in this section is the logarithm of monthly CPI in Italy, France and the UK. The sample period goes from 1957Q3 to 2007Q3 in all three countries, and the data source is the IMF's International Financial Statistics published on the IMF webpage.

Figure 1 displays plots of the three time series, as well as the first 50 sample autocorrelation values, and the periodograms computed at the discrete Fourier frequencies $\lambda_{\mathrm{j}}=2 \pi \mathrm{j} / \mathrm{T}, \mathrm{j}=1,2, \ldots, \mathrm{T} / 2$.

\section{[Insert Figures 1 and 2 about here]}

The sample autocorrelation values are all significantly positive and decay very slowly. Also, the periodograms exhibit the highest values at the smallest frequency. Both features might be an indication of nonstationarity and possibly of fractional integration behaviour. Figure 2 is similar to Figure 1 but based on the first-differenced data, that is, the inflation rates in the three countries. The correlograms still suggest here that the series are nonstationary, and the periodograms still present a large peak at the zero frequency (as well as other smaller peaks at the seasonal frequencies), which may suggest that the inflation rate series are fractionally integrated.

The first model we consider is the standard I(d) one with seasonal autoregressions. We allow for different seasonal $\mathrm{AR}(\mathrm{k})$, (with $\mathrm{k}=1,2$ and 3) processes, and using standard 
likelihood criteria we conclude that the AR(1) model is sufficient to describe the seasonal short-run dynamics. In other words, we estimate the model,

$$
y_{t}=\mu+x_{t} ; \quad(1-L)^{d} x_{t}=u_{t} ; \quad u_{t}=\rho u_{t-4}+\varepsilon_{t}, \quad t=1,2, \ldots,
$$

for the two cases of no regressors (i.e., $\mu=0$ in (M1)) and an intercept ( $\mu$ unknown) respectively. Here, we employ a Whittle estimate in the frequency domain (Dahlhaus, 1989), along with a version of the tests of Robinson (1994) that is suitable for this type of model. The results are reported in Table 1.

\section{[Insert Table 1 about here]}

It can be seen that the results vary substantially depending on the inclusion or not of an intercept in the model. If $\mu=0$, the estimated values of $d$ are slightly below 1 in the three cases and the unit root null hypothesis cannot be rejected in any of the three countries. However, if an intercept is included, $d$ is found to be significantly above 1 in all cases, being equal to 1.549 for France, 1.552 for Italy, and 1.307 for the UK. Moreover, the intercept is statistically significant in all three countries, suggesting that it should be included in the model. Thus, according to this specification, inflation may be well described in terms of a long-memory $\mathrm{I}(\mathrm{d})$ process with $\mathrm{d}$ ranging between 0 and 1 , and being nonstationary $(\mathrm{d}>0.5)$ in the case of France and Italy.

In the second specification we assume that the seasonal structure can also be described in terms of a long-memory process and consider a model of the form:

$y_{t}=\mu+x_{t} ; \quad\left(1-L^{s}\right)^{d} x_{t}=u_{t} ; \quad u_{t} \approx I(0), \quad t=1,2, \ldots$

again for the two cases of no intercept $(\mu=0)$ and an intercept respectively, and we assume now that the $\mathrm{I}(0)$ disturbances $\mathrm{u}_{\mathrm{t}}$ are white noise and $\mathrm{AR}(1)$. The results, based on another version of Robinson's (1994) tests are displayed in Table 2. 


\section{[Insert Table 2 about here]}

As in the previous table, the results are very sensitive to the inclusion or not of an intercept. Specifically, in the uncorrelated case, the estimated values of $d$ are smaller than 1 without intercepts, while they are substantially above if an intercept is included in the regression model. If we allow for autocorrelation in the error term in the form of an AR(1) process, the orders of integration are much smaller than in the uncorrelated case, being even negative if an intercept is included. These results are highly influenced by the AR coefficient that is in the three cases very close to 1 . This clearly indicates that the component at the zero-frequency plays a very important role when modelling these series. When performing Likelihood Ratio (LR) tests to determine if there is weak dependence, the results support the white noise specification in the three countries.

\section{[Insert Table 3 about here]}

Finally, we consider a 3-factor Gegenbauer process for the three inflation rate series. ${ }^{4}$ In Table 3 again we display the results for the two cases of white noise and AR(1) $\mathrm{u}_{\mathrm{t}}$, based on Robinson's (1994) parametric tests. Starting with the uncorrelated case (in Table 3(i)), it can be seen that the results are now very similar in the two cases of $\mu=0$ and $\mu$ unknown. For France, the three orders of integration are about $0.32,0.08$ and 0.17 respectively for the $0, \pi$ and $\pi / 2$ frequencies. In the case of Italy these values are $0.27,0.03$ and 0 , and for the UK they are about $0.18,0.04$ and 0 . In the case of $\mathrm{AR}(1)$ disturbances, there are some differences: the order of integration at the zero frequency is smaller for all

\footnotetext{
${ }^{4}$ Since we are now modelling the inflation rate series we initially take first differences of the log CPI series at the long-run or zero frequency.
} 
three series than in the previous case of white noise $\mathrm{u}_{\mathrm{t}}$, probably owing to the competition with the AR coefficient in describing the nonstationarity at the zero frequency, and, in the case of France, the orders of integration at the seasonal frequencies are now higher. For Italy and the UK, we still find a value of 0 at the semi-annual frequency $(\pi / 2)$, suggesting that there is no long-memory component at this frequency in these two countries. Thus, in Table 4 we assume a 2 -factor Gegenbauer process for these two countries. ${ }^{5}$

\section{[Insert Table 4 about here]}

Assuming that the disturbances are white noise the results are the same with or without intercepts. For Italy, the orders of integration are 0.275 and 0.032 respectively for the zero and the seasonal $(\pi)$ frequencies, and for UK the corresponding values are 0.179 and 0.029 . In all cases, the estimates are significantly different from zero. When imposing AR disturbances (in Table 4(ii)), the estimates are all negative, once more probably owing to the competition with the AR parameters in describing time dependence. ${ }^{6}$

In summary, having considered the three models described above, the preferred specification for each country is the following. For France:

$y_{t}=2.2384+x_{t} ; \quad(1-L)^{1.549} x_{t}=u_{t} ; \quad u_{t}=0.331 u_{t-4}+\varepsilon_{t}$,

$$
y_{t}=2.2890+x_{t} ; \quad\left(1-L^{4}\right)^{1.652} x_{t}=\varepsilon_{t},
$$

and

\footnotetext{
5 Note that $\mathrm{d}_{2}$ (the order of integration at the semi-annual frequency), though small in magnitude, is statistically significant in all cases.

${ }^{6}$ Though not reported, the AR coefficients were once more very close to 1 in all cases.
} 
$(1-L) y_{t}=\pi_{t} ; \quad \pi_{t}=-0.0142+x_{t}$, $(-2.402)$

$\left(1-2 \cos w_{r}^{(1)} L+L^{2}\right)^{0.314}\left(1-2 \cos w_{r}^{(2)} L+L^{2}\right)^{0.081}\left(1-2 \cos w_{r}^{(3)} L+L^{2}\right)^{0.168} x_{t}=\varepsilon_{t}$,

t-values in parenthesis and, given that $w_{r}^{(1)}=0, w_{r}^{(2)}=\pi, w_{r}^{(3)}=\pi / 2$, the second equation in (M3-F) can be written as:

$$
(1-L)^{0.628}(1+L)^{0.162}\left(1+L^{2}\right)^{0.168} x_{t}=\varepsilon_{t}
$$

For Italy,

$$
y_{t}=1.5802+x_{t ;} \quad(1-L)^{1.552} x_{t}=u_{t} ; \quad u_{t}=0.024 u_{t-4}+\varepsilon_{t},
$$

$$
y_{t}=1.5960+x_{t} ; \quad\left(1-L^{4}\right)^{1.806} x_{t}=\varepsilon_{t},
$$

and

$$
(1-L) y_{t}=\pi_{t} ; \quad \pi_{t}=0.0098+x_{t},
$$

$\left(1-2 \cos w_{1} L+L^{2}\right)^{0.275}\left(1-2 \cos w_{2} L+L^{2}\right)^{0.032} x_{t}=\varepsilon_{t}$,

or, alternatively,

$$
(1-L)^{0.550}(1+L)^{0.064} x_{t}=\varepsilon_{t},
$$

and finally, for the UK,

$$
\begin{aligned}
& y_{t}=1.9468+x_{t} ; \quad(1-L)^{1.307} x_{t}=u_{t} ; \quad u_{t}=0.482 u_{t-4}+\varepsilon_{t}, \\
& \text { (175.72) } \\
& y_{t}=1.9549+x_{t} ; \quad\left(1-L^{4}\right)^{1.723} x_{t}=\varepsilon_{t} \text {, } \\
& \text { (162.45) }
\end{aligned}
$$

and 
$(1-L) y_{t}=\pi_{t} ; \quad \pi_{t}=0.0122+x_{t}$,

$\left(1-2 \cos w_{1} L+L^{2}\right)^{0.179}\left(1-2 \cos w_{2} L+L^{2}\right)^{0.029} x_{t}=\varepsilon_{t}$,

or, alternatively,

$$
(1-L)^{0.358}(1+L)^{0.058} x_{t}=\varepsilon_{t} \text {. }
$$

\section{Forecasting comparisons}

In this section, we use forecasting performance criteria to select the best model specification in each case. Specifically, we use the last 20 observations for an in-sample forecasting experiment. Standard measures of forecast accuracy are the following: Theil's $\mathrm{U}$, the mean absolute percentage error (MAPE), the mean-squared error (MSE), the rootmean-squared error (RMSE), the root-mean-percentage-squared error (RMPSE) and the mean absolute deviation (MAD) (Witt and Witt, 1992). However, all these measures are purely descriptive. There exist several statistical tests for comparing different forecasting models. One of these tests, widely employed in the time series literature, is the asymptotic test for a zero expected loss differential of Diebold and Mariano (1995). ${ }^{7}$ However, Harvey, Leybourne and Newbold (1997) note that the Diebold-Mariano test statistic could be seriously over-sized as the prediction horizon increases, and therefore provide a modified Diebold-Mariano test statistic given by:

$$
M-D M=D M \sqrt{\frac{n+1-2 h+h(h-1) / n}{n}},
$$

where DM is the original Diebold-Mariano statistic, $\mathrm{h}$ is the prediction horizon and $\mathrm{n}$ is the time span for the predictions. Harvey et al. (1997) and Clark and McCracken (2001) show

\footnotetext{
7 An alternative approach is the bootstrap-based test of Ashley (1998), though this method is computationally more intensive.
} 
that this modified test statistic performs better than the DM test statistic, and also that the power of the test is improved when p-values are computed with a Student distribution.

Using the M-DM test statistic (and based on the RMSEs), we further evaluate the relative forecast performance of the different models by making pairwise comparisons. We consider 5- and 10-period ahead forecasts on a 20-period horizon. The results are displayed in Table $5 .^{8}$

\section{[Insert Table 5 about here]}

We indicate in bold in this table, for each prediction-horizon and each country, the rejections of the null hypothesis that the forecast performance of model (Mi) and model (Mj) is equal in favour of the one-sided alternative that model (Mi)'s performance is superior at the $5 \%$ significance level. We note that the results are similar for the two time horizons, though they vary across countries. In all three countries (M2) and (M3) outperform (M1), implying that a model with a long-memory component exclusively affecting the long-run or zero frequency is inappropriate in all cases. However, when comparing (M2) with (M3), the results are radically different from one country to another: in the case of France (M2) outperforms (M3); for Italy, it cannot be established whether (M2) is superior to (M3) or vice versa, while for the UK (M3) produces significant better statistical results than (M2).

On the basis of these results, model (M2-F) is the preferred specification for France, implying the existence of a seasonal long-memory component, with equal order of integration at zero and the seasonal frequencies (this order of integration being equal to 1.652). In other words, inflation in France is a nonstationary seasonal long-memory

\footnotetext{
${ }^{8}$ For the 15 (and higher period)-period forecasts there is not found superiority of one model over the others.
} 
process, with an order of integration of about 0.652. For Italy, models (M2-I) and (M3-I) have a comparable forecasting performance, but given the higher flexibility allowed by (M3-I) we choose this specification for this country. In this case, inflation is also nonstationary with a large component of long memory at the zero frequency and a smaller one at the semi-annual frequency (see equation (11)). Finally, for the UK, the best specification seems to be (M3-UK), namely a two-factor Gegenbauer process, one factor corresponding to the zero frequency $\left(\mathrm{d}_{1}=0.258\right)$ and the other one to the semi-annual frequency $\left(\mathrm{d}_{2}=0.058\right)$ (equation (12)). According to this specification, UK inflation is a stationary long-memory process.

\section{Conclusions}

This paper has analysed the stochastic behaviour of inflation in three European countries (France, Italy and the UK) using a general framework, namely a multi-factor long-memory process that allows for different fractional differencing parameters at each frequency. The flexibility of the model, based on Gegenbauer processes, is a very desirable feature compared with more restrictive approaches previously used in the literature on inflation which impose the same degree of integration at all frequencies in the spectrum. (see, e.g., Backus and Zin, 1993, and Hassler and Wolters, 1995). Our results can be summarised as follows. Inflation in France and Italy is nonstationary, but in the former country this applies to both the long-run and the seasonal frequencies, whilst for the latter the nonstationarity concerns exclusively the long-run or zero frequency, and the contribution of the long-range dependence in the seasonal structure is relatively small. For the UK, inflation seems to be stationary, though with a large component of long-memory behaviour, especially at the zero frequency. 
Our results indicate that inflation is a very persistent phenomenon, at least for the three countries examined here. The fact that the I(1) hypothesis is decisively rejected in all three cases implies that the series are mean-reverting, with shocks disappearing in the long run but very slowly, especially in France, and to a lesser extent in Italy and the UK. Moreover, we have shown that seasonality matters, with a positive though small degree of long-range dependence.

Our analysis could be extended by taking into account the possibility of structural breaks, stochastic volatility or non-linearities. These are clearly important issues, whose linkages with fractional processes have hardly been investigated until now, although they have already attracted the attention of some researchers. Future work will focus on them. 


\section{References}

Adelman, I., 1965, Long cycles: Fact or artifacts. American Economic Review 55, 444463.

Andel, J., 1986, Long memory time series models, Kybernetika 22, 105-123.

Ashley, R., 1998, A new technique for postsample model selection and validation, Journal of Economics Dynamics and Control 22, 647-665.

Backus, D. and S. Zin, 1993, Long memory inflation uncertainty. Evidence from the term structure of interest rates. Journal of Money, Credit and Banking 25, 681-700.

Baillie, R.T., Bollerslev, T., and H.O. Mikkelsen, 1996, Fractionally integrated generalized autoregressive conditional heteroscedasticity. Journal of Econometrics, 3-30.

Baillie, R.T., C.F. Chung and M.A. Tieslau, 1996, Analyzing inflation by the fractionally integrated ARFIMA-GARCH Model. Journal of Applied Econometrics 11, 23-40.

Barkoulas, J.T. and C.F. Baum, 2006, Long memory forecasting of US monetary indices. Journal of Forecasting 25, 291-302.

Barsky, R.B., 1987, The Fisher hypothesis and the forecastability and persistence of inflation. Journal of Monetary Economics, 3-24.

Baum, C.F., J. Barkoulas and M. Caglayan, 1999, Persistence in the international inflation rates. Southern Economic Journal 65, 900-913.

Bollerslev, T., and H.O. Mikkelsen, 1996, Modeling and pricing long memory in stock market volatility. Journal of Econometrics, 1-29.

Bollerslev, T. and j.h. Wright, 2000, Semiparametric estimation of long memory dependencies: the role of high-frequency data. Journal of Econometrics, 81-106.

Bos, C., P.H. Franses and M. Ooms, 1999, Long memory and level shifts: Reanalyzing inflation rates. Empirical Economics 24, 427-450. 
Bos, C., P.H. Franses and M. Ooms, 2001, Inflation, forecast intervals and long memory regression models. International Journal of Forecasting 18, 243-264.

Chambers, M., 1998, Long memory and aggregation in macroeconomic time series. International Economic Review, 1053-1072.

Chung, C.-F., 1996a, A generalized fractionally integrated autoregressive moving-average process, Journal of Time Series Analysis 17, 111-140.

Chung, C.-F., 1996b, Estimating a generalized long memory process, Journal of Econometrics 73, 237-259.

Chung, C.-F. and R.T. Baillie, 1993, Small sample bias in conditional sum of squares estimators of fractionally integrated ARMA models. Empirical Economics, 791-806.

Clark, T.E. and M.W. McCracken, 2001, Tests of forecast accuracy and encompassing for nested models, Journal of Econometrics 105, 85-110.

Dahlhaus, R., 1989, Efficient parameter estimation of self-similar process, Annals of Statistics 17, 1749-1766.

Dalla, V. and J. Hidalgo, 2005, A parametric bootstrap test for cycles, Journal of Econometrics 129, 219-261.

Delgado, M. and P.M. Robinson, 1994, New methods for the analysis of long memory time series. Application to Spanish inflation. Journal of Forecasting 13, 97-107.

Dickey, D.A., D.P. Hasza and W.A. Fuller, 1984, Testing for unit roots in seasonal time series, Journal of the American Statistical Association 79, 355-367.

Diebold, F.X. and A. Inoue, 2001, Long memory and regime switching, Journal of Econometrics 105, 131-159.

Ferrara, L. and D. Guegan, 2001a, Comparison of parameter estimation methods in cyclical long memory time series, in Developments in Forecast Combination and Portfolio Choice, Dunis, C., Timmermann, A., and J. Moody eds., Wiley, New York, 179-195. 
Ferrara, L. and D. Guegan, 2001b, Forecasting with k-factor Gegenbauer processes. Theory and Applications. Journal of Forecasting 20, 581-601.

Franses, N. Hyung and J. Penn, 2006, Structural breaks and long memory in US inflation rates. Do they matter for forecasting. Research in International Business and Finance 20, 95-110.

Franses, P.H. and M. Ooms, 1997, A periodic long memory model for quarterly UK inflation. International Journal of Forecasting 13, 117-126.

Gadea, M.D., M. Sabate and J.M. Serrano, 2004, Structural breaks and their trace in the memory. Inflation rate series in the long run. Journal of International Financial Markets, Institutions and Money 14, 117-134.

Gil-Alana, L.A., 2002, Seasonal long memory in the aggregate output, Economics Letters 74, 333-337.

Gil-Alana, L.A., 2007, Testing the existence of multiple cycles in financial and economic time series. Annals of Economics and Finance 1, 1-20.

Gil-Alana, L.A., 2008, Fractional integration and structural breaks at unknown periods of time, Journal of Time Series Analysis 29, 163-185.

Gil-Alana, L.A. and P.M. Robinson, 2001, Testing of seasonal fractional integration in the UK and Japanese consumption and income. Journal of Applied Econometrics 16, 95-114. Guegan, D., 2000, A new model: the k-factor GIGARCH process. Journal of Signal Processing, 265-271.

Granger, C.W.J., 1966, The typical spectral shape of an economic variable. Econometrica $37,150-161$.

Gray, H.L., Zhang, N. and Woodward, W.A., 1989, On generalized fractional processes, Journal of Time Series Analysis 10, 233-257. 
Gray, H.L., Zhang, N. and Woodward, W.A., 1994, On generalized fractional processes. A correction, Journal of Time Series Analysis 15, 561-562.

Harvey, D.I., S.J. Leybourne and P. Newbold, 1997, Testing the equality of prediction mean squared errors, International Journal of Forecasting 13, 281-291.

Hassler, U., 1993, Regression of spectral estimators with fractionally integrated time series. Journal of Time Series Analysis 14, 369-380.

Hassler, U. and J. Wolters, 1995, Long memory in inflation rates. International evidence. Journal of Business and Economic Statistics 13, 37-45.

Hylleberg, S., R. F. Engle, C. W. J. Granger and B. S. Yoo, 1990, Seasonal integration and cointegration, Journal of Econometrics 44, 215-238.

Ling, S. and W.K. Li, 1997, On fractionally integrated autoregressive moving average time series models with conditional heteroscedasticity. Journal of the American Statistical Association, 1184-1187.

Magnus, W., Oberhettinger, F. and R.P. Soni, 1966, Formulas and theorems for the special functions of mathematical physics. Springer, Berlin.

Porter-Hudak, S., 1990, An application of the seasonal fractionally differenced model to the monetary aggregate. Journal of the American Statistical Association 85, 338-344.

Rainville, E.D., 1960, Special functions, MacMillan, New York.

Rose, A.K., 1988, “Is the real interest rate stable?”. Journal of Finance, 1095-1112.

Sadek, N. and A. Khotanzad, 2004, K-factor Gegenbauer ARMA process for network traffic simulation. Computers and Communications 2, 963-968.

Witt, S.F. and C.A. Witt, 1992, Modelling and forecasting demand in tourism. San Diego, Academic Press. 
Figure 1: Time series plots with correlograms and periodograms

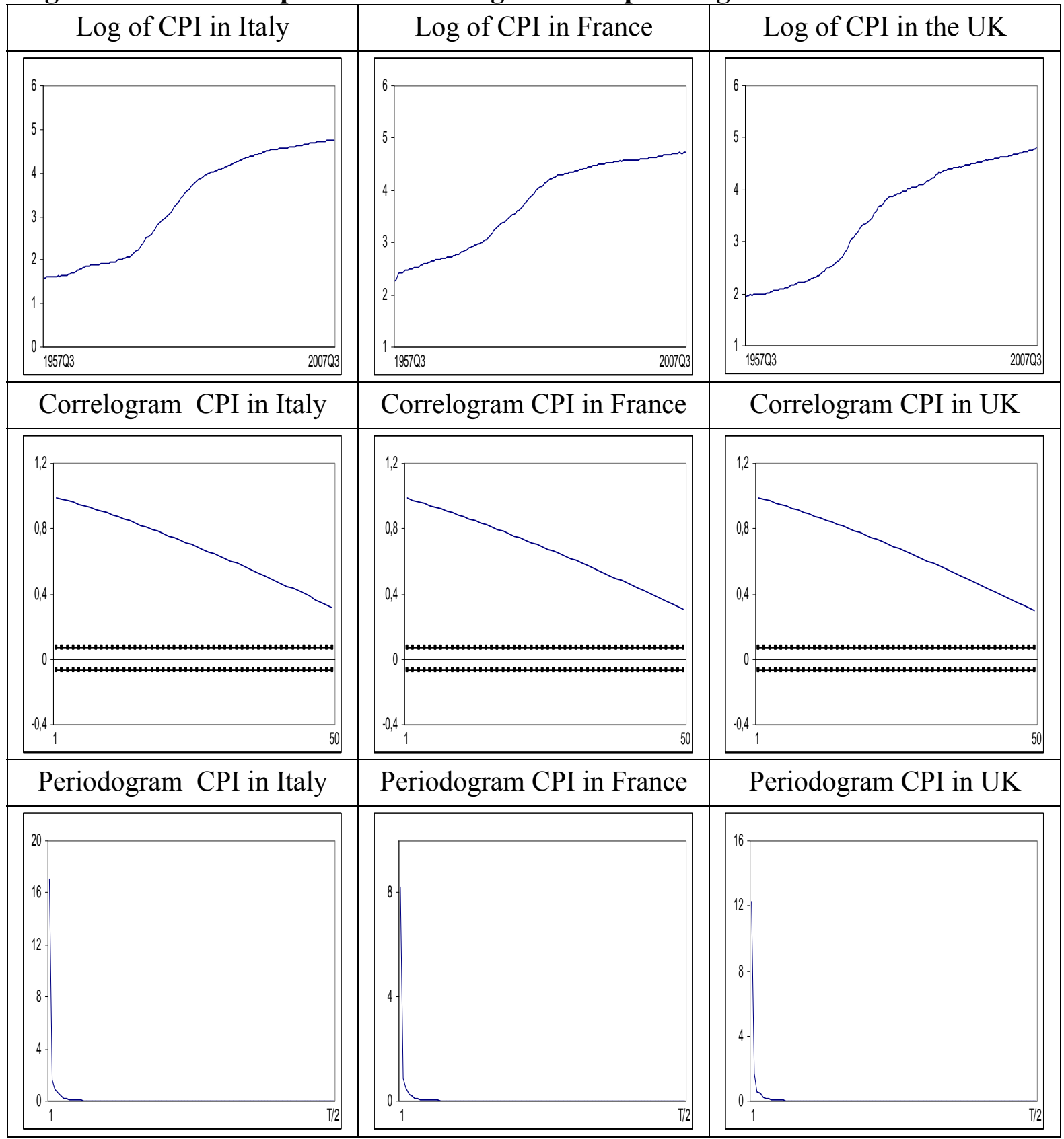

The large sample standard error under the null hypothesis of no autocorrelation is $1 / \sqrt{ }$ T or roughly 0.070 for the series used in this application. The periodograms are computed based on the discrete frequencies $\lambda_{j}=2 \pi \mathrm{j} / \mathrm{T}$. 
Figure 2: First differences of the series with correlograms and periodograms

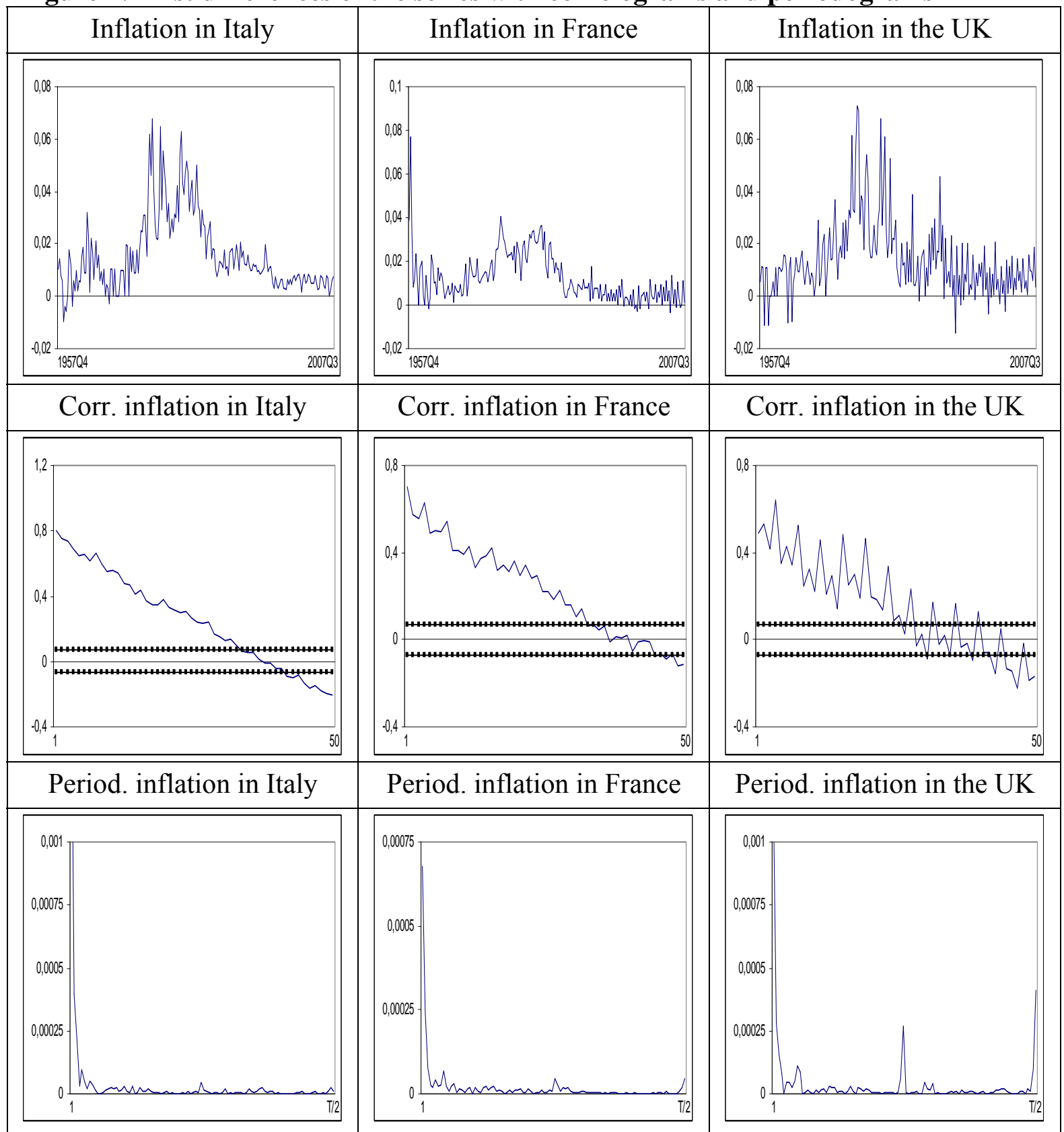

The large sample standard error under the null hypothesis of no autocorrelation is $1 / \sqrt{ } \mathrm{T}$ or roughly 0.070 for the series used in this application. The periodograms are computed based on the discrete frequencies $\lambda_{\mathrm{j}}=2 \pi \mathrm{j} / \mathrm{T}$. 
Table 1: Estimates of the parameters in model (M1): I(d) with seasonal AR(1)

\begin{tabular}{|c|c|c|c|c|c|}
\hline & \multicolumn{2}{|c|}{ No regressors } & \multicolumn{3}{c|}{ An intercept } \\
\hline & $\mathrm{d}$ & Seas. AR & $\mathrm{d}$ & Intercept & Seas. AR \\
\hline \multirow{2}{*}{ FRANCE } & $\begin{array}{c}0.966 \\
(0.707,1.131)\end{array}$ & 0.166 & $\begin{array}{c}\mathbf{1 . 5 4 9} \\
(\mathbf{1 . 4 3 8 , 1 . 7 0 7 )}\end{array}$ & $\begin{array}{c}\mathbf{2 . 2 3 8 4} \\
\mathbf{( 3 5 4 . 5 8 )}\end{array}$ & $\mathbf{0 . 3 3 1}$ \\
\hline ITALY & $\begin{array}{c}0.957 \\
(0.768,1.100)\end{array}$ & 0.115 & $\begin{array}{c}\mathbf{1 . 5 5 2} \\
\mathbf{( 1 . 4 8 7} \mathbf{1 . 6 3 2})\end{array}$ & $\begin{array}{c}\mathbf{1 . 5 8 0 2} \\
\mathbf{( 2 2 4 . 3 8 )}\end{array}$ & $\mathbf{0 . 0 2 4}$ \\
\hline U.K. & $\begin{array}{c}0.968 \\
(0.723,1.103)\end{array}$ & 0.016 & $\begin{array}{c}\mathbf{1 . 3 0 7} \\
\mathbf{( 1 . 2 2 5 , 1 . 4 1 0 )}\end{array}$ & $\begin{array}{c}\mathbf{1 . 9 4 6 8} \\
\mathbf{( 1 7 5 . 7 2 )}\end{array}$ & $\mathbf{0 . 4 8 2}$ \\
\hline
\end{tabular}

In bold, the significant models according to likelihood criteria. In parenthesis (in the $2^{\text {nd }}$ and $4^{\text {th }}$ columns) the $95 \%$ confidence bands for the values of $d$. In the $5^{\text {th }}$ column, they are t-values.

Table 2: Estimates of the parameters in model (M2): Seasonal I(d)

\begin{tabular}{|c|c|c|c|c|c|}
\hline & \multicolumn{5}{|c|}{ i) White noise disturbances } \\
\hline & \multicolumn{2}{|c|}{ No regressors } & \multicolumn{3}{|c|}{ An intercept } \\
\hline & $\mathrm{d}$ & AR coeff. & $\mathrm{d}$ & Intercept & Seas. AR \\
\hline FRANCE & $\begin{array}{c}0.914 \\
(0.798,1.040)\end{array}$ & $\operatorname{xxxxx}$ & $\begin{array}{c}1.652 \\
(1.580,1.739)\end{array}$ & $\begin{array}{l}2.28902 \\
(214.82)\end{array}$ & $\operatorname{xxxxx}$ \\
\hline ITALY & $\begin{array}{c}0.849 \\
(0.724,0.992)\end{array}$ & $\operatorname{xxxxx}$ & $\begin{array}{c}1.806 \\
(1.737,1.887)\end{array}$ & $\begin{array}{l}1.59599 \\
(144.22)\end{array}$ & $\operatorname{xxxxx}$ \\
\hline \multirow[t]{4}{*}{ U.K. } & $\begin{array}{c}0.852 \\
(0.704,0.996)\end{array}$ & $\operatorname{xxxxx}$ & $\begin{array}{c}1.723 \\
(1.641,1.825)\end{array}$ & $\begin{array}{l}1.95494 \\
(162.45)\end{array}$ & $\operatorname{xxxxx}$ \\
\hline & \multicolumn{5}{|c|}{ ii) $\mathrm{AR}(1)$ disturbances } \\
\hline & \multicolumn{2}{|c|}{ No regressors } & \multicolumn{3}{|c|}{ An intercept } \\
\hline & $\mathrm{d}$ & AR coeff. & $\mathrm{d}$ & Intercept & Seas. AR \\
\hline FRANCE & $\begin{array}{c}0.197 \\
(0.190,0.206)\end{array}$ & 0.986 & $\begin{array}{c}-0.150 \\
(-0.388,0.061)\end{array}$ & $\begin{array}{l}3.74244 \\
(423.98)\end{array}$ & 0.999 \\
\hline ITALY & $\begin{array}{c}0.295 \\
(0.285,0.308)\end{array}$ & 0.991 & $\begin{array}{c}-0.182 \\
(-0.367,0.068)\end{array}$ & $\begin{array}{l}3.26953 \\
(297.55)\end{array}$ & 0.999 \\
\hline U.K. & $\begin{array}{c}0.243 \\
(0.234,0.255)\end{array}$ & 0.988 & $\begin{array}{c}-0.200 \\
(-0.358,0.064)\end{array}$ & $\begin{array}{l}3.46846 \\
(368.19)\end{array}$ & 0.999 \\
\hline
\end{tabular}

In bold, the significant models according to likelihood criteria. In parenthesis (in the $2^{\text {nd }}$ and $4^{\text {th }}$ columns) the $95 \%$ confidence bands for the values of $\mathrm{d}$. In the $5^{\text {th }}$ column, they are $\mathrm{t}$-values. 
Table 3: Estimates of the parameters in model (M3): 3-factor Gegenbauer I(d)

\begin{tabular}{|c|c|c|c|c|c|c|c|}
\hline & \multicolumn{7}{|c|}{ i) White noise disturbances } \\
\hline & \multicolumn{3}{|c|}{ No regressors } & \multicolumn{4}{|c|}{ An intercept } \\
\hline & $\mathrm{d}_{1}$ & $\mathrm{~d}_{2}$ & $\mathrm{~d}_{3}$ & $\mathrm{~d}_{1}$ & $\mathrm{~d}_{2}$ & $\mathrm{~d}_{3}$ & Interc. \\
\hline FRANCE & $\begin{array}{c}0.331 \\
(0.291,0.406)\end{array}$ & $\begin{array}{c}0.077 \\
(0.055,0.108)\end{array}$ & $\begin{array}{c}0.170 \\
(0.125,0.227)\end{array}$ & $\begin{array}{c}0.314 \\
(0.287,0.348)\end{array}$ & $\begin{array}{c}0.081 \\
(0.058,0.112)\end{array}$ & $\begin{array}{c}0.168 \\
(0.123,0.226)\end{array}$ & $\begin{array}{l}-.0142 \\
(-2.402)\end{array}$ \\
\hline ITALY & $\begin{array}{c}0.272 \\
(0.252,0.296)\end{array}$ & $\begin{array}{c}0.030 \\
(0.008,0.059)\end{array}$ & $\begin{array}{c}0.000 \\
(-.058,0.039)\end{array}$ & $\begin{array}{c}0.271 \\
(0.253,0.294)\end{array}$ & $\begin{array}{c}0.029 \\
(0.009,0.054)\end{array}$ & $\begin{array}{c}0.000 \\
(-.080,0.053)\end{array}$ & $\begin{array}{c}0.0091 \\
(1.182)\end{array}$ \\
\hline \multirow[t]{4}{*}{ U.K. } & $\begin{array}{c}0.179 \\
(0.156,0.211)\end{array}$ & $\begin{array}{c}0.038 \\
(0.012,0.066)\end{array}$ & $\begin{array}{c}0.000 \\
(-0.89,0.073) \\
\end{array}$ & $\begin{array}{c}0.178 \\
(0.155,0.191) \\
\end{array}$ & $\begin{array}{c}0.037 \\
(0.011,0.059)\end{array}$ & $\begin{array}{c}0.000 \\
(-0.61,0.046)\end{array}$ & $\begin{array}{c}0.0122 \\
(2.848)\end{array}$ \\
\hline & \multicolumn{7}{|c|}{ ii) $\mathrm{AR}(1)$ disturbances } \\
\hline & \multicolumn{3}{|c|}{ No regressors } & \multicolumn{4}{|c|}{ An intercept } \\
\hline & $\mathrm{d}_{1}$ & $\mathrm{~d}_{2}$ & $d_{3}$ & $\mathrm{~d}_{1}$ & $\mathrm{~d}_{2}$ & $\mathrm{~d}_{3}$ & Interc. \\
\hline FRANCE & $\begin{array}{c}0.135 \\
(0.068,0.267)\end{array}$ & $\begin{array}{c}0.156 \\
(0.104,0.491)\end{array}$ & $\begin{array}{c}0.197 \\
(0.139,0.283)\end{array}$ & $\begin{array}{c}0.020 \\
(-.063,0.131)\end{array}$ & $\begin{array}{c}0.305 \\
(0.127,0.589)\end{array}$ & $\begin{array}{c}0.204 \\
(0.135,0.311)\end{array}$ & $\begin{array}{l}0.0119 \\
(32.501)\end{array}$ \\
\hline ITALY & $\begin{array}{c}0.140 \\
(0.069,0.255) \\
\end{array}$ & $\begin{array}{c}0.083 \\
(0.048,0.131) \\
\end{array}$ & $\begin{array}{c}0.000 \\
(-.091,0.071) \\
\end{array}$ & $\begin{array}{c}0.137 \\
(0.068,0.248) \\
\end{array}$ & $\begin{array}{c}0.081 \\
(0.050,0.129) \\
\end{array}$ & $\begin{array}{c}0.000 \\
(-.097,0.058) \\
\end{array}$ & $\begin{array}{c}0.0139 \\
(6.894) \\
\end{array}$ \\
\hline U.K. & $\begin{array}{c}0.054 \\
(0.006,0.132)\end{array}$ & $\begin{array}{c}0.078 \\
(0.055,0.104)\end{array}$ & $\begin{array}{c}0.000 \\
(-.047,0.037)\end{array}$ & $\begin{array}{c}0.018 \\
(-.086,0.149)\end{array}$ & $\begin{array}{c}0.030 \\
(0.007,0.102)\end{array}$ & $\begin{array}{c}0.000 \\
(-.049,0.057)\end{array}$ & $\begin{array}{l}0.0141 \\
(14.720)\end{array}$ \\
\hline
\end{tabular}

In bold, the significant models according to likelihood criteria. 
Table 4: Estimates of the parameters in model (M3): 2-factor Gegenbauer I(d)

\begin{tabular}{|c|c|c|c|c|c|}
\hline & \multicolumn{5}{|c|}{ i) White noise disturbances } \\
\hline & \multicolumn{2}{|c|}{ No regressors } & \multicolumn{3}{|c|}{ An intercept } \\
\hline & $\mathrm{d}_{1}$ & $\mathrm{~d}_{2}$ & $\mathrm{~d}_{1}$ & $\mathrm{~d}_{2}$ & Intercept \\
\hline ITALY & $\begin{array}{c}0.275 \\
(0.250,0.306)\end{array}$ & $\begin{array}{c}0.033 \\
(0.006,0.069)\end{array}$ & $\begin{array}{c}0.275 \\
(0.208,0.307)\end{array}$ & $\begin{array}{c}0.032 \\
(0.005,0.067)\end{array}$ & $\begin{array}{c}0.00898 \\
(1.9473)\end{array}$ \\
\hline \multirow[t]{4}{*}{ U.K. } & $\begin{array}{c}0.179 \\
(0.157,0.208)\end{array}$ & $\begin{array}{c}0.030 \\
(0.010,0.055)\end{array}$ & $\begin{array}{c}0.179 \\
(0.156,0.208)\end{array}$ & $\begin{array}{c}0.029 \\
(0.009,0.054)\end{array}$ & $\begin{array}{c}0.01221 \\
(2.7631)\end{array}$ \\
\hline & \multicolumn{5}{|c|}{ i) $\mathrm{AR}(1)$ disturbances } \\
\hline & \multicolumn{2}{|c|}{ No regressors } & \multicolumn{3}{|c|}{ An intercept } \\
\hline & $\mathrm{d}_{1}$ & $\mathrm{~d}_{2}$ & $\mathrm{~d}_{1}$ & $\mathrm{~d}_{2}$ & Intercept \\
\hline ITALY & $\begin{array}{c}-0.552 \\
(-.703,-.441)\end{array}$ & $\begin{array}{c}-0.281 \\
(-.381,-.183)\end{array}$ & $\begin{array}{c}-1.000 \\
(-1.537,-.960)\end{array}$ & $\begin{array}{c}-0.480 \\
(-.543,-.207)\end{array}$ & $\begin{array}{c}0.01683 \\
(438.73)\end{array}$ \\
\hline U.K. & $\begin{array}{c}-0.663 \\
(-.841,-.477)\end{array}$ & $\begin{array}{c}-0.153 \\
(-.317,-.031)\end{array}$ & $\begin{array}{c}-0.952 \\
(-1.217,-.883)\end{array}$ & $\begin{array}{c}-0.237 \\
(-.251,-.217)\end{array}$ & $\begin{array}{c}0.01551 \\
(253.91)\end{array}$ \\
\hline
\end{tabular}

In bold, the significant models according to likelihood criteria. 
Table 5: M-DM statistics with $h=5$ and $h=10$

\begin{tabular}{|c|c|c|c|c|c|}
\hline \multicolumn{3}{|c|}{$\mathrm{h}=5$} & \multicolumn{3}{|c|}{$\mathrm{h}=10$} \\
\hline FRANCE & M1-F & M2-F & FRANCE & M1-F & M2-F \\
\hline M2-F & $\begin{array}{c}4.272 \\
\text { (M2-F) }\end{array}$ & XXXXX & M2-F & $\begin{array}{c}2.892 \\
\text { (M2-F) }\end{array}$ & XXXXX \\
\hline M3-F & $\begin{array}{c}4.172 \\
\text { (M3-F) }\end{array}$ & $\begin{array}{c}-7.805 \\
\text { (M2-F) }\end{array}$ & M3-F & $\begin{array}{c}2.812 \\
\text { (M3-F) }\end{array}$ & $\begin{array}{c}-5.284 \\
(M 2-F)\end{array}$ \\
\hline ITALY & M1-I & M2-I & ITALY & M1-I & M2-I \\
\hline M2-I & $\begin{array}{c}4.370 \\
(\mathrm{M} 2-\mathrm{I})\end{array}$ & XXXXX & M2-I & $\begin{array}{c}2.958 \\
(\mathrm{M} 2-\mathrm{I})\end{array}$ & XXXXX \\
\hline M3-I & $\begin{array}{c}4.291 \\
\text { (M3-I) }\end{array}$ & $\begin{array}{l}1.349 \\
(----)\end{array}$ & M3-I & $\begin{array}{c}2.905 \\
\text { (M3-I) }\end{array}$ & $\begin{array}{c}0.913 \\
(----)\end{array}$ \\
\hline UK & M1-UK & M2-UK & UK & M1-UK & M2-UK \\
\hline M2-UK & $\begin{array}{c}4.117 \\
(\mathrm{M} 2-\mathrm{UK})\end{array}$ & XXXXX & M2-UK & $\begin{array}{c}2.787 \\
(\mathrm{M} 2-\mathrm{UK})\end{array}$ & XXXXX \\
\hline M3-UK & $\begin{array}{c}4.191 \\
\text { (M3-UK) }\end{array}$ & $\begin{array}{c}4.161 \\
\text { (M3-UK) }\end{array}$ & M3-UK & $\begin{array}{c}2.837 \\
\text { (M3-UK) }\end{array}$ & $\begin{array}{c}2.817 \\
\text { (M3-UK) }\end{array}$ \\
\hline
\end{tabular}

In bold, the cases where one of the models outperforms the other at the $5 \%$ level. The critical value at the $5 \%$ level with 19 degrees of freedom is 1.729 . 